\title{
Agricultural flood and drought risk reduction by a proposed multi-purpose dam: A case study of the Malwathoya River Basin, Sri Lanka
}

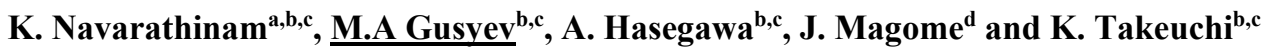 \\ ${ }^{a}$ Department of Irrigation, Sri Lanka \\ ${ }^{b}$ International Centre for Water Hazard and Risk Management (ICHARM) under the auspices of UNESCO, Public \\ Works Research Institute (PWRI), Tsukuba, Japan \\ ${ }^{c}$ National Graduate Institute for Policy Studies (GRIPS), Tokyo, Japan \\ ${ }^{d}$ International Research Centre for River Basin Environment (ICRE), Interdisciplinary Graduate School of Medicine and \\ Engineering, University of Yamanashi, Kofu, Japan
}

Email: gusyev55@pwri.go.jp; maksymgusyev@gmail.com

\begin{abstract}
In this study, we investigate the role of a proposed multi-purpose dam for flood and drought risk reduction in the Malwathoya River Basin, Sri Lanka. The Malwathoya River Basin is the second largest basin in Sri Lanka with an area of $3,246 \mathrm{~km}^{2}$ located in the dry zone of northern Sri Lanka. The river basin has an average annual rainfall of $1200 \mathrm{~mm}$ with two distinct dry and wet seasons and has an elevation range between 350 above mean sea level (AMSL) in the mountainous areas and 0 AMSL near the sea shore. For the lower part of the river basin, the dry season rice production of $170 \mathrm{~km}^{2}$ area cannot be fully utilized due to annual precipitation of less than $750 \mathrm{~mm}$ and lack of irrigation water, which is diverted from the Malwathu River at the Thekkam diversion weir to large water storage tanks via a cascaded irrigation scheme. In the wet season, the rice paddies are frequently flooded due to intense rainfall from the North East monsoon between October and January as well as the inter monsoon during April causing severe economic losses during 2012 and 2014 floods. As a result, a multi-purpose dam with the capacity of 210 million cubic meters (MCM) was proposed in the middle of the Malwathoya River Basin to reduce flood peak discharges during wet season and to supply irrigation water for the Thekkam diversion weir during dry season.

In our methodology, a holistic approach of combined drought and flood assessment is adopted for the multipurpose dam operation. From this point of view, opposite actions are required for the risk reductions: the full reservoir storage should be maintained before the start of the dry season and the low levels are necessary for the flood peak reduction during flood season. For the hazard severity assessment, the long-term precipitation record has been investigated with the use of Standardized Precipitation Index (SPI) as well of Standardized Precipitation Evapotranspiration Index (SPEI) to select the most severe dry and wet seasons. In addition, past agricultural damages caused by 2012-2014 floods and droughts were correlated using the Normalized Difference Vegetation Index (NDVI) and Land Surface Water Index (LSWI) with field data at several locations. For the dam operation simulation, the 30-arcsec (about 1-km) grid distributed hydrological model BTOP was constructed from the global data sets and included reservoirs and medium water storage tanks with total capacity of $540 \mathrm{MCM}$ located upstream of the Thekkam diversion weir. The BTOP model simulation with the ground-based precipitation was calibrated with observed river discharge data at the diversion weir and had a satisfactory statistical performance. Then, the calibrated BTOP model was used to simulate multi-purpose dam operation with the short- and long-term precipitation. From the BTOP model results, the proposed dam allowed us to establish an optimum operation for the flood and drought risk reduction and indicated a decrease in water related hazards. In addition, we estimated a standardized inflow index (SII) and a standardized reservoir storage index (SRSI) from the BTOP simulated reservoir inflows and water storage to demonstrate long-term dam performance on the same scale with SPI and SPEI values. As a result, this study demonstrates a combined flood and drought risk assessment from the water resources infrastructure point of view and allows us to reduce farmers' vulnerability in the northern region of Sri Lanka.
\end{abstract}

Keywords: $\quad$ BTOP model, flood discharge, agricultural drought, SPI, SPEI, SII, SRSI 
Navarathinam et al., Agricultural flood and drought risk reduction by a proposed multi-purpose dam: A case study of the Malwathoya River Basin, Sri Lanka

\section{INTRODUCTION}

Floods and droughts are frequent natural hazards in Sri Lanka. They cause major economic losses in the dry part of the country such as the Malwathoya River basin, which is located in the northern part of Sri Lanka. In the Malwathoya River basin, $67.90 \mathrm{~km}^{2}$ of rice paddies were damaged during wet season by 2011 flood, $48.55 \mathrm{~km}^{2}$ by 2012 flood and $93.12 \mathrm{~km}^{2}$ by and 2014 flood, while 2011 and 2014 droughts damaged about $2,200 \mathrm{~km}^{2}$ of dry season rice paddies (DMC, 2012; OCHA, 2014). In addition, a cascaded system of medium reservoirs and thousands of small water tanks exists to store river water in the wet season and to distribute this water during the dry season to meet irrigation water demands. However, this cascaded system, which is the special feature of Sri Lanka, provides only limited flood and drought mitigation in the Malwathoya River basin. For example, relatively small volumes, simple overflow operation, siltation and low safety level of these small tanks are the factors that do not allow proper flood mitigation during high intensity Monsoon rainfall and drought mitigation during pro-longed dry-spells (Navarathinam, 2015). To mitigate impacts of these potential disasters, the Ministry of Irrigation and Water Resources Management (MIWRM) has proposed construction of Malwathoya dam based on a feasibility study conducted in the Malwathoya River basin by the USSR government in 1960 (Technopromexport, 1960).

The aim of this study is to investigate the effectiveness of the proposed dam in mitigation of flood and drought disasters in the agricultural part of the lower Malwathoya basin. The proposed dam enables an increase of rice cropping area and a reduction of flood peak discharges via better regulation of water availability. In this study, we utilize global and local data to understand the hydrological behavior of the basin with indices and numerical model simulations. The standardized and satellite-based indices are adopted to characterize the disaster occurrences in the irrigated paddy area. For the numerical simulations, a distributed hydrologic model is utilized to simulate low, normal and flood flows with and without the proposed dam including the existing reservoirs and small tanks in the Malwathoya basin. From the results of our simulations, we establish an effective operation rule with flood peak reduction during high intensity rainfall events while considering irrigation water supply during prolonged drought spells by maximizing rice cropping intensity during wet and dry seasons.

\section{THE MALWATHOYA RIVER BASIN}

In Sri Lanka, the Malwathoya River basin is the second largest river basin with a catchment area of 3,246 $\mathrm{km}^{2}$ (Figure 1). The basin is situated in a dry zone of the country and receives an average annual rainfall of $1200 \mathrm{~mm}$ while the lower part of the basin (Mannar District) receives less than $900 \mathrm{~mm}$ of annual rainfall, which is insufficient to support dry season agriculture. In the basin, the total water storage volume of 6 major reservoirs, 146 medium tanks and more than 1240 small tanks is about 570 million cubic meters (MCM) and is used to irrigate an area of $654 \mathrm{~km}^{2}$. These small water storage tanks have a surface area between 1.5 and $3.0 \mathrm{~km}^{2}$ and are connected into a cascaded system, which is the unique characteristic of the Malwathoya River basin (Bandara, 2009). For the lower part of the basin, the Thekkam diversion weir is located a few kilometers upstream of Mannar District and diverts river water for irrigation of $170 \mathrm{~km}^{2}$ during rice cultivation (Figure 1). For the irrigation water, the Giant's Tank with $40 \mathrm{MCM}$ capacity is located in the Eastern side of the Mannar District and serves as a buffer between the Thekkam weir and rice paddies. The proposed dam with $210 \mathrm{MCM}$ capacity and an upstream catchment area of $2142 \mathrm{~km}^{2}$ is designed to mitigate frequent floods and droughts in the lower part of the Malwathoya River basin by flood peak reduction and water supply regulation (Figure 1).

For the local hydro-meteorological data, we obtained daily rainfall data from six gauging stations from 1990 to 2014 and monthly totals between 1950 and 1975 (Figure 1). The daily river discharges were obtained at the Thekkam diversion weir from 1990 to 2014. The These river discharge data are interpreted from river water levels and are of a poor quality at flood events due to frequent weir damages. In addition, daily inflows of the Pavatkulam reservoir were also obtained from 1993 to 2014. The precipitation data is utilized for the BTOP model input and the observed discharges for the BTOP model calibration.

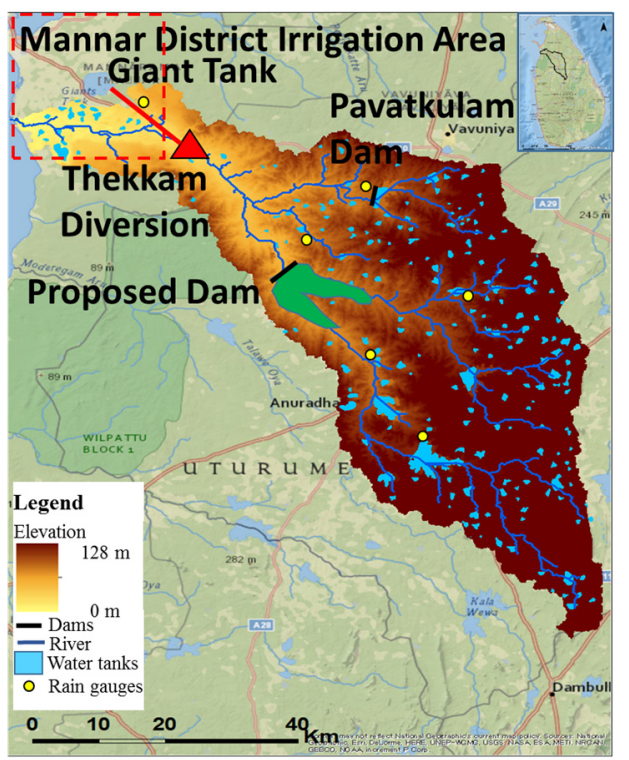

Figure 1. Features of the Malwathoya River Basin, Sri Lanka. 
Navarathinam et al., Agricultural flood and drought risk reduction by a proposed multi-purpose dam: A case study of the Malwathoya River Basin, Sri Lanka

\section{METHODOLOGY}

\subsection{Drought and flood assessment}

We conducted a combined flood and drought assessment to investigate the effectiveness of the proposed dam to mitigate floods and droughts in the lower part of Malwathoya River Basin. In Step 1, the available local and global datasets were collected for the Malwathoya River basin. In Step 2, historical floods and droughts were quantified using standardized indices of Standardized Precipitation Index (SPI) and Precipitation Evapotranspiration Index (SPEI), and satellite-based indices of Normalized Difference Vegetation Index (NDVI) and Land Surface Water Index (LSWI). In Step 3, the BTOP model, which is a distributed hydrological model based on modified topographic index (Takeuchi et al., 2008), was setup with the collected datasets including current infrastructure of small and medium tanks as well as reservoirs. The BTOP model was calibrated to local river discharge data and used to simulate past flood and drought events at the Thekkam weir and the proposed dam location. In Step 4, the calibrated BTOP model with the proposed dam was utilized to conduct short- and long-term simulation for the flood and drought mitigation in the lower part of the basin. In addition, the simulated inflows and water volume of the proposed dam were used to calculate a standardized inflow index (SII) and a standardized reservoir storage index (SRSI).

\subsection{Standardized indices}

The standardized indices (SPI, SII, and SRSI) were calculated using the WMO (2012) tool and SPEI was obtained from the global SPEI database (Vicente-Serrano et al., 2010). The standardized indices are obtained by fitting the long-term record to a cumulative distribution function (CDF) of gamma distribution and these CDFs are then transformed into a normal distribution (McKee et al., 1993). The SPI was computed from local precipitation (McKee et al., 1993), the SII was estimated from simulated total monthly dam inflows and SRSI was estimated from a sum of these inflows and a monthly average of simulated reservoir volume (Gusyev et al., 2015a). SPEI is calculated as a difference between precipitation and potential evapotranspiration and is transformed by several available distributions except gamma (Vicente-Serrano et al., 2010). The resulted standardized indices (SPI, SII, SRSI and SPEI) have the same range of values indicating wet climate with positive values and dry climates with negative values such as moderate drought from -1.0 to -1.49, severe drought from -1.50 to -1.99, and extreme drought below -2.0 (McKee et al.,1993).

\subsection{Satellite-based indices}

The satellite-based indices such as NDVI and LSWI have been effectively used to identify historical droughts and floods (Chandraseker et al., 2008). For both indices, the range is from -1.0 to 1.0 and the flood events are indicated by low NDVI and high LSWI. The drought can be characterized by comparison of higher three month time series value of NDVI and LSWI. In this study, NDVI and LSWI indices were computed using 16-day composite data obtained from LP DAAC (2015). The NDVI was determined as NDVI=(NIRIR)/(NIR+IR), where NIR and IR are the percentage reflected radiation in the near infrared portion and the red portion of the spectrum, respectively. The LSWI was calculated as LSWI=(NIR-SWIR)/(NIR+SWIR), where SWIR is the short wave infrared portion of the spectrum.

\subsection{BTOP model of the Malwathoya River Basin}

We utilized the global datasets to setup a 30-arcsec (about 1-km) grid BTOP model of the Malwathoya River basin and local data were used for the model input and calibration. The BTOP model was constructed using HydroSHEDS digital elevation model (DEM) data (Lehner et al., 2008). In the BTOP model, we utilized potential evapotranspiration estimated by the Shuttleworth-Wallace model (Zhou et al., 2006) using climate forcing data CRU TS3.1 (UEA CRU, 2012) and a monthly NDVI (Tucker et al., 1994). For the existing water infrastructure, we combined small and medium water tanks into 16 clusters and also included five major reservoirs with the proposed dam in the BTOP model (Gusyev et al., 2015a,b). The location of these combined reservoirs was selected based on the flow accumulation network. For the Malwathoya River basin, the BTOP model was subdivided into four blocks based on locations of two existing dams and the Thekkam diversion weir (Navarathinam, 2015). These blocks were calibrated against observed dam inflows and river discharges and the Nash-Sutcliffe efficiency (NSE) was used as the BTOP model performance indicator (Moriasi et al., 2007).

In the BTOP model, two types of dam operation were simulated: a multi-purpose dam operation (type " 31 ") and water tanks (type "32"). The type "31" dam operation has a primary purpose of irrigation water supply, which is based on water volume in the reservoir and irrigation diversion requirement (IDR), and a secondary 
Navarathinam et al., Agricultural flood and drought risk reduction by a proposed multi-purpose dam: A case study of the Malwathoya River Basin, Sri Lanka

purpose of the flood control (Gusyev et al., 2015a,b). The IDR is calculated for the irrigated area located downstream of the Thekkam diversion weir (Navarathinam, 2015). For the type "32" operation, water tanks have no flood control and only store water to meet IDR of the irrigated areas. In both operation types, the BTOP model calculates IDR as a product of effective rainfall, crop coefficient $\left(\mathrm{K}_{\mathrm{c}}\right)$ and irrigation efficiency (Gusyev et al, 2015). In this study, the $\mathrm{K}_{\mathrm{c}}$ values were estimated from number of days of rice growing period (FAO, 1998) based on current cropping calendar of dry and wet seasons for the irrigated area of the lower Malwathoya River basin.

\section{RESULTS AND DISCUSSION}

\subsection{Standardized indices}

In Figure 2, 3-month SPI and SPEI demonstrate a similar pattern of historical floods and droughts. Prior to 1984, no extreme dry seasons, which are defined by SPI and SPEI values below -2, are indicated while several extremely wet seasons are shown with SPI and SPEI values above 2. For example, the flood event in 1957 is considered a 100-year flood and is demonstrated by an extremely wet season in 1957. After year 1985, the trends of both SPI and SPEI show an increase in frequency of severe and extreme droughts while having a similar severity of floods during wet seasons. For example, the recent droughts in year 2010, 2012 and 2014 and floods in year 2011, 2012 and 2014 are also indicated by SPI and SPEI. However, there is a significant difference in terms of frequency and magnitude of droughts between SPI and SPEI.

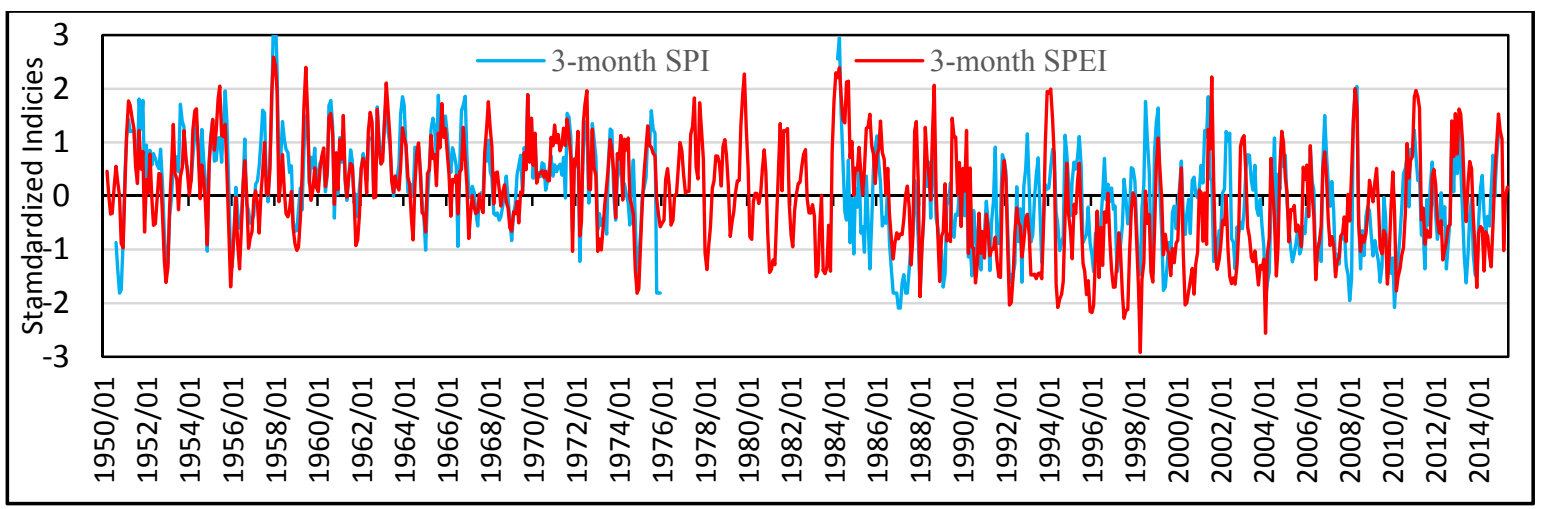

Figure 2. Standardized indices of SPI and SPEI in the Malwathoya River basin.

\subsection{Satellite-based indices}

In Figure 3, NDVI and LSWI values are demonstrated from October to December at the Mannar District paddy areas. For the 2012 and 2014 floods in December, NDVI values have two sharp declines compared with "normal" year. These NDVI declines indicate the totally damaged paddy areas due to flood inundation that occurred during the initial and development stages of wet season cultivation and are consistent with LSWI values. In both 2012 and 2014 floods, the LSWI values are higher due to flood inundation that occurred during these flood events. For the 2013 drought, the drought occurred during mid- and late-stage of dry season rice cultivation and both NDVI and LSWI values are lower between June and August 2013/2014 compared to June-August 2012/2013. The lower NDVI values indicate drought damages to rice crops while the lower LSWI values indicate a completely empty Giant's Tank with without standing water, which is usually available for irrigation. As a result, the remote sensing analysis provides useful information about stage of crop failure due to floods and droughts in the paddy field area of the lower Malwathoya basin and can be a useful tool for monitoring agricultural flood and drought risks.

\subsection{Short-term BTOP simulation of 2012 flood and drought}

Figure 4 demonstrates the BTOP simulation with type " 31 " dam operation of the proposed dam for wet and dry cultivation seasons in 2012. The importance of including existing water storage tanks in the BTOP model is illustrated for the Thekkam diversion weir in Figure 4a. The improvement of simulated river discharges is also indicted by the NSE increase from 0.524 to 0.774 . In Figure 4, the observed river discharges at the Thekkam weir show low flows up to December 2012 due to the long dry period and high river discharges due to runoff starting from middle of October 2012. The simulated BTOP discharges without the existing water storage infrastructure are overestimated from October to December. This is due to the fact that the most of river discharge is captured by these water storages with no outflow and only the irrigation water diversion is 
Navarathinam et al., Agricultural flood and drought risk reduction by a proposed multi-purpose dam: A case study of the Malwathoya River Basin, Sri Lanka

used for the paddies. Once these water storages are refilled, the simulated and observed discharges become similar and flood peak discharges are not reduced by existing storages due to full storage. For the simulated discharges, the BTOP model with type "32" operation (existing storages with irrigation diversion) have a better fit to the observed discharges from October to December. This illustrates a satisfactory calibration of the BTOP model and the calibrated BTOP model is utilized to simulate flood peak reduction at the Thekkam weir during 2012.

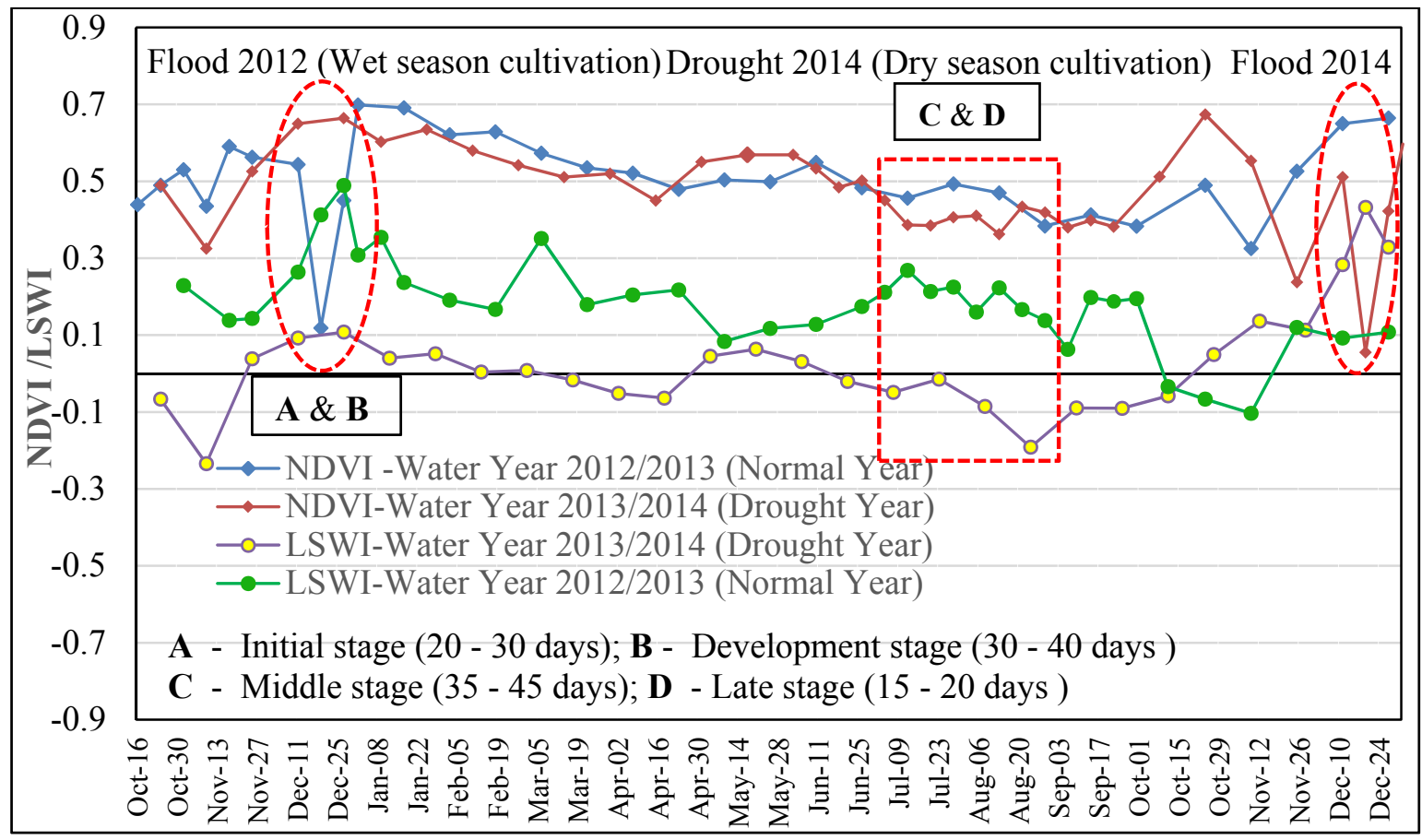

Figure 3. Estimated NDVI and LSWI for the irrigated paddy area of the Mannar District. The flood and drought events are indicated by dashed lines.

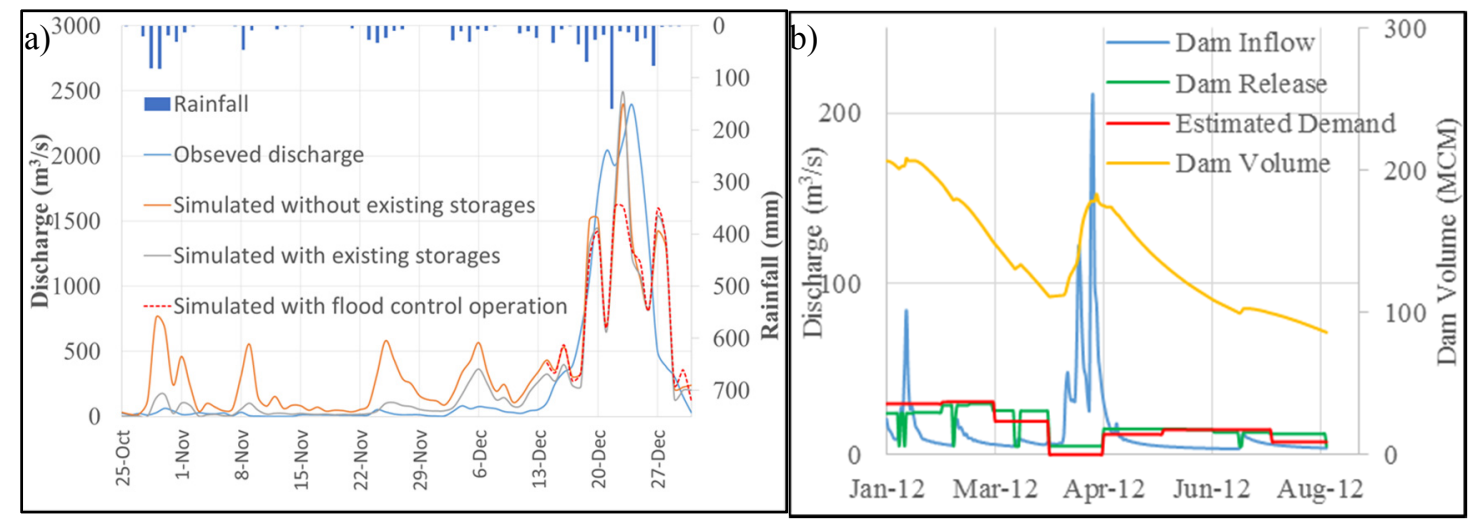

Figure 4. BTOP simulation in year 2012 for flood control at the Thekkam diversion weir (a) and irrigation water supply using the proposed dam operation (b).

In the proposed dam, the flood operation with initial water volume of $40 \mathrm{MCM}$ is able to reduce the flood peak at Thekkam diversion by about $800 \mathrm{~m}^{3} / \mathrm{s}$ for the 2012 flood season (not shown). This result indicates a suitability of the proposed dam for flood mitigation in the lower part of the basin. For drought mitigation, the proposed dam utilizes the captured peak inflows during the wet season for rice cultivation from January to March. In Figure 4b, the initial dam storage of about $180 \mathrm{MCM}$ is used by type " 31 " dam operation to determine the irrigable area at the lower part of the basin for 2012 dry season. In this case, the simulated IDR allows Mannar District to utilize $73 \mathrm{~km}^{2}$ out of $170 \mathrm{~km}^{2}$ from May to August during the dry season of 2012. For the historical 2012 dry season cultivation, Mannar District utilized only $33 \mathrm{~km}^{2}$ and had $22 \mathrm{~km}^{2}$ of the drought affected paddy areas. In this case, the total potential benefit of the proposed dam is a sum of avoided economic losses (labor, fertilizers, seeds, etc.) due to damaged rice paddies and the potential income from 62 
Navarathinam et al., Agricultural flood and drought risk reduction by a proposed multi-purpose dam: A case study of the Malwathoya River Basin, Sri Lanka

$\mathrm{km}^{2}$ of irrigated area. As a result, the calibrated BTOP model provides river basin level important information that can used for water resources development and planning of the flood and drought mitigation.

\subsection{Long-term BTOP simulation of the proposed dam}

In Figure 5, the long-term BTOP simulation of proposed dam inflows and volume are simulated between 1990 and 2014. These simulated results are used to estimate 3-month SII and SRSI indices, which are demonstrated in the bottom of Figure 5. These 3-month SII and SRSI indices are demonstrated with 3-month SPI and SPEI presented in Figure 2. In previous studies, feasibility of a proposed dam was conducted by using a synthetic hydrograph technique; therefore, the long-term BTOP simulation assists to obtain flood peak discharge of different return periods. From this simulation, the daily dam inflows from 2010 are higher compared to the flood discharges between 1900 and 2012. This pattern is also indicated by SII. For the dam storage, the proposed dam is refilled up to its full storage during wet seasons to meet IDRs during the dry season. However, the full dam capacity may not be sufficient to cover the entire dry season cultivation during extreme droughts. For example, SPI, SPEI and SRSI indices show that 1992 has severe drought climatic conditions while SII demonstrates an extreme severity drought. This implies that the dam inflows play an important part in the dry season irrigation and should be considered together with the dam water volume in the future analysis. In addition, the standardized indices provide important information for mitigating flood and droughts in the entire Malwathoya River basin.
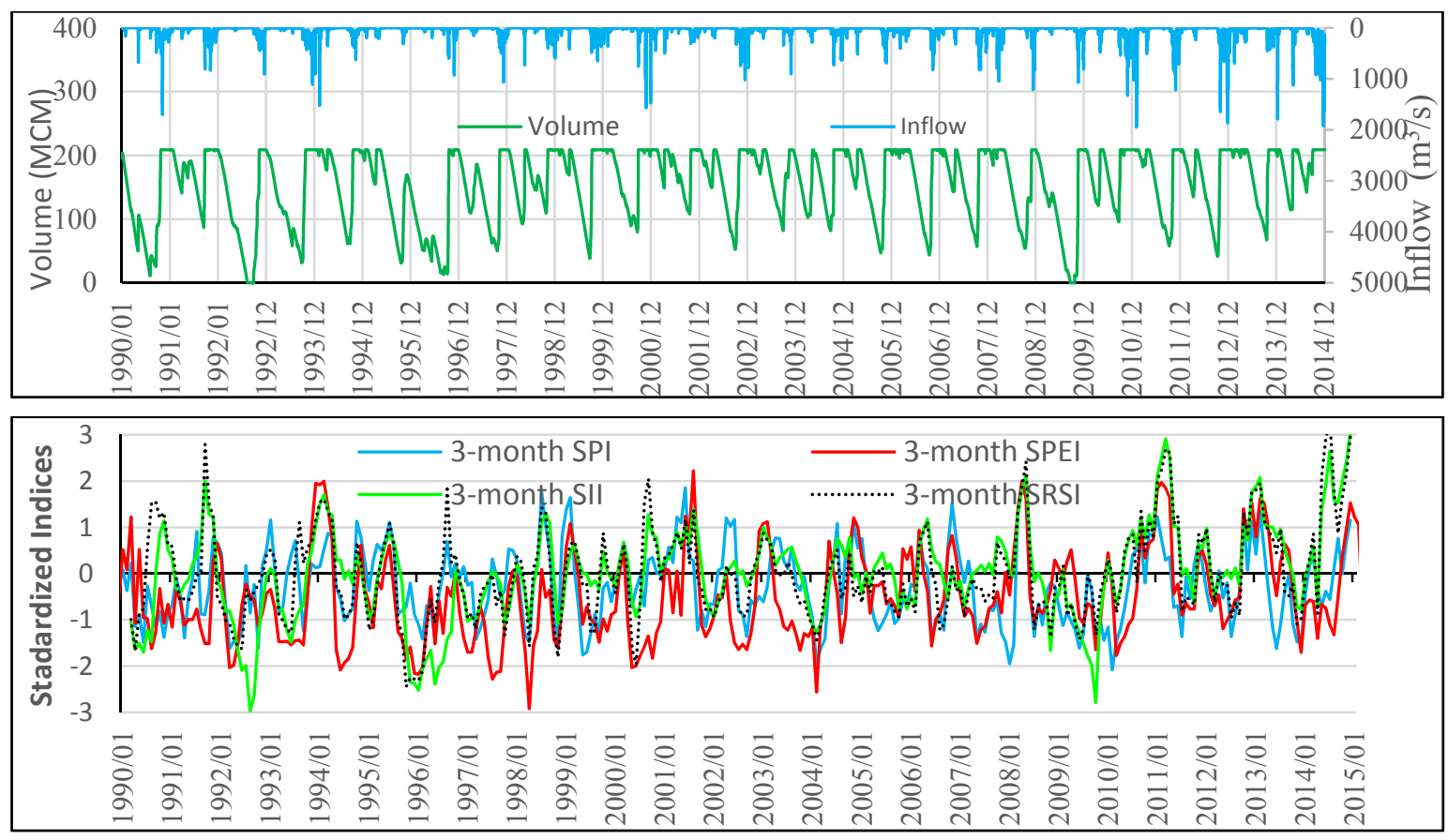

Figure 5. Simulated dam inflows and volume by the BTOP model (top) and 3-month SII and SRSI indices from this simulation as well as 3-month SPI and SPEI indices (bottom).

\section{CONCLUDING REMARKS}

In this study, we utilized a comprehensive approach of standardized indices (SPI, SII, SRSI, and SPEI), satellite-based indicators (NDVI and LSWI), and BTOP model simulations to investigate the proposed multipurpose dam in flood and drought risk reduction. We estimated SPI with local data and obtained SPEI from global dataset and were used to provide information about meteorological droughts and wet climates in the Malwathoya river basin. The analysis of NDVI and LSWI indices was adapted to provide information about rice paddies affected by recent droughts and floods in the lower part of the river basin. The affected area was determined by a comparison of NDVI and LSWI in normal and drought/flood years indicating disaster timing, duration and stages of crop failure. In addition, the study area has a dense number of surface water features indicating that LSWI could be an important indicator of water availability indicator in water storage tanks. For the BTOP model improvement, thousands of water storage tanks have been combined in 21 clusters of water infrastructure with irrigated area to simulate complex interactions in the river basin.

From the BTOP simulation, the proposed dam provides mitigation of floods and droughts for the lower part of the Malwathoya River basin. For the flood control operation, the proposed dam with flood operation 
Navarathinam et al., Agricultural flood and drought risk reduction by a proposed multi-purpose dam: A case study of the Malwathoya River Basin, Sri Lanka

reduces the flood peak by about $800 \mathrm{~m}^{3} / \mathrm{s}$ at the Thekkam diversion weir. The long-term BTOP simulation indicates that the proposed dam is refilled every year during the wet season and has available water for dry season cultivation. The SII and SRSI indices describe reservoir inflows and storages of existing water infrastructure in the entire basin. In addition, SPEI may be a calculated with local data to demonstrate agricultural droughts. In case of the past droughts, the proposed dam contributes to the success the wet and dry season rice cultivation by fully utilizing paddy area in the lower part of the basin. As a result, the calibrated BTOP model provides useful information at river basin level for water resources development and planning of flood and drought mitigation.

\section{REFERENCES}

Bandara, C.M. (2009). Village tanks cascade systems of Sri Lanka, University of Peradeniya, Sri Lanka.

Chandrasekar, K., Sesha Sai, M.V.R., Roy, P.S., and Dwevedi, R.S. (2008). Land Surface Water Index (LSWI) response to rainfall and NDVI using the MODIS Vegetation Index product, International Journal of Remote Sensing 31(15): 3987-4005.

Disaster Management Center (DMC). (2012). Progress Report, Mannar District, Sri Lanka

Food and Agriculture Organization (FAO) (1998). Crop Evapotranspiration. FAO 56 Irrigation and Drainage Paper. FAO of the United Nations, Rome, Italy, $286 \mathrm{p}$.

Gusyev, M., Magome, J., Kuribayashi D., Sawano, H., and Lee, S. (2015a). Drought assessment in the Pampanga River basin, the Philippines - Part 1: Characterizing a role of dams in historical droughts with standardized indices. In Proceedings of the 21st International Congress on Modelling and Simulation (MODSIM 2015), November $29^{\text {th }}-$ December $4^{\text {th }}$, Queensland, Australia.

Gusyev, M.A., A. Hasegawa, J. Magome, H. Umino, and H. Sawano (2015b). Drought assessment in the Pampanga River basin, the Philippines - Part 3: Evaluating climate change impacts on dam infrastructure with standardized indices. In Proceedings of the 21st International Congress on Modelling and Simulation (MODSIM 2015), November $29^{\text {th }}-$ December $4^{\text {th }}$, Queensland, Australia.

Lehner, B., Verdin, K., and Jarvis, A. (2008). New global hydrography derived from spaceborne elevation data. Eos, Transactions 89(10): 93-94, http://hydrosheds.cr.usgs.gov

The Land Processes Distributed Active Archive Center (LP DAAC) (2015). the Moderate Resolution Imaging Spectroradiometer (MODIS) data. USGS Earth Resources Observation and Science (EROS) Center, Sioux Falls, South Dakota (https://lpdaac.usgs.gov), accessed March 1, 2015.

McKee, T.B., Doesken, N.J., and Kleist, J. (1993). The relationship of drought frequency and duration to time scales. In Proceedings of the 8th Conference on Applied Climatology (Vol. 17, No. 22, pp. 179-183). Boston, MA: American Meteorological Society.

Navarathinam, K. (2015). Assessment of the Proposed Malwathoya Dam for Flood and Drought Mitigation in the Lower Malwathoya River Basin, Sri Lanka. Master Thesis, the National Graduate Institute for Policy Studies (GRIPS), Tokyo, Japan, 61 p.

Office for the Coordination of Humanitarian Affairs (OCHA). (2014). Humanitarian Bulletin, Sri Lanka, Issue 03/Aug 2014, OCHA.

Takeuchi, K., Hapuarachchi, H., Zhou, M., Ishidaira, H., and Magome, J. (2008). A BTOP model to extend TOPMODEL for distributed hydrological simulation of large basins. Hydrol. Process. 22: 3236-3251.

Technopromexport (1960). Feasibility Report, Lower Malwathoya Project, Irrigation Department, Ceylon and Technopromexport, Moscow, USSR.

Tucker, C. J., Pinzon, J.E., and Brown, M.E. (1994). Global Inventory Modeling and Mapping Studies, NA94apr15b.n11-VIg, 2.0, Global Land Cover Facility, University of Maryland, College Park.

Vicente-Sarrano, S.M, Begueriya, S., and Lopez-Moreno, J.I. (2010). A multisaclar drought index Sensitive to global warming: The standardized precipitation evapotranspiration index. J. Climate 23: 1696-1718.

World Meteorological Organization (WMO) (2012). Standardized Precipitation Index User Guide (M. Svoboda, M. Hayes, and D. Wood). WMO-No. 1090, Geneva.

Zhou, M.C., Ishidaira, H., Hapuarachchi, H.P., Magome, J., Kiem, A.S., and Takeuchi, K. (2006). Estimating potential evapotranspiration using the Shuttleworth-Wallace model and NOAA-AVHRR NDVI to feed the hydrological modeling over the Mekong River Basin. Journal of Hydrology 327: 151-173. 